\title{
Investigation of Cold Forming Cracking Defect of High-Strength Vehicle Structural Steel
}

\author{
Kai-Yu CUI ${ }^{\mathrm{a},{ }^{*}}$, Xiao-Yu YEb ${ }^{\mathrm{b}}$, Zheng-Rong $\mathrm{LI}^{\mathrm{c}}$ and Xue-Gang XIONG ${ }^{\mathrm{d}}$ \\ Pangang Group Research Institute Co., Ltd. \\ Panzhihua, Sichuan, China \\ acuiky@qq.com, byexiaoyupzh@163.com, c13982357532@163.com, dxuegangxiong@163.com
}

Keywords: high-strength vehicle structural steel; cold bending forming; crack; liquation TiN; TiC precipitate.

\begin{abstract}
The reason of high-strength vehicle structural steel cracked during cold bending was investigated. The large liquation TiN distributed in grain and the group gathered by multiple liquation TiN can be origin of crack, the mismatching of forming mould leads to large processing stress thereby causing cracking, the metallographic structure showing blurry grain boundaries and cementites gathered there restrains crack propagation hardly, thereby intergranular fracture occurs easily, the fracture morphology characterizes cleavage fracture, macroscopic appearance is brittle fracture.
\end{abstract}

\section{Introduction}

With the rapid development of vehicle manufacturing industry, nowadays the environmental pollution caused by vehicle emission is increasingly serious. Lightweight of vehicle is an effective method to realize energy conservation and emission reduction, according to some researches, roughly $10 \%$ weight decrease will lead to $6 \%-8 \%$ fuel consumption reduction and $4 \%$ harmful gas emission reduction[1-3]. As an important material applied in vehicles, steel with high strength has became an inevitable developing trend to realize vehicle lightweight meanwhile assuring safety.

However, steel with high strength will lead to the increase of processing difficulty and producing cost, therefore it is a significant research direction to improve the formability of high-strength steel. In this article, the reason of high-strength vehicle structural steel sheet cracked during cold bending forming was investigated, thereby providing theoretical support for formability improvement of high-strength vehicle structural steel.

\section{Experimental Material and Method}

The experimental material was vehicle structure part (thickness: $3.3 \mathrm{~mm}$ ) which cracked during bending forming. Table I shows the chemical composition, $\mathrm{Ti}$ micro-alloying technology is applied to realize high strength.

The experimental material was sampled for mechanical performance test, microstructure observation and fracture analysis. The samples for mechanical performance test were carried out through SHT5605-P tester, microstructure observation were eroded in 3\% nitric acid alcohol solution, and then observed through ZEISS MEF3 metallographic microscope. SEM was carried out through FEI-MLA 600 SEM with a scanning voltage of $20 \mathrm{kV}$ to measure the fracture morphology, and energy spectrum analysis was carried out through METEK- EDAX EDS to analyze the precipitates. TEM was applied through JEM-2100 to observe precipitates. 


\section{Experimental Results}

\section{Macroscopic Analysis}

Macroscopic feature and defect position of specimen are shown in Figure 1. It is obvious that the specimen cracked at the position where suffering $90^{\circ}$ bending, and the appearance of this position shows the phenomenon of metal flaked.

\section{Mechanical Performance}

Mechanical performance of specimen is shown in Table II. Yield strength exceeds $700 \mathrm{MPa}$ and tensile strength approaches $800 \mathrm{MPa}$, meanwhile elongation and yield ratio are good.

\section{Metallographic Structure}

Metallographic structures near crack and at normal position are contrasted. As shown in Figure 2, (1) there are deformed microstructure and obvious extrusion on grains at the edge structure near crack; (2) metallographic structures near crack and at normal position are similar: grain boundaries of ferrite are blurry, showing incomplete recrystallization phenomenon, and a little of spherical pearlites and many cementites at grain boundaries; (3) there are some rectangular large precipitates, size is around $5-10 \mu \mathrm{m}$, based on the size and chemical composition of experimental specimen, the precipitates are defined as liquation TiN.

TABLE I. Chemical Composition of Cracked Specimen /\%

\begin{tabular}{|c|c|c|c|c|c|c|c|c|}
\hline $\mathbf{C}$ & $\mathbf{S i}$ & $\mathbf{M n}$ & $\mathbf{P}$ & $\mathbf{S}$ & $\mathbf{N b}$ & $\mathbf{T i}$ & $\mathbf{A l s}$ & $\mathbf{N}$ \\
\hline $0.06-$ & $0.15-$ & $1.35-$ & \multirow{2}{*}{$\leq 0.020$} & \multirow{2}{*}{$\leq 0.010$} & $0.015-$ & $0.080-$ & $0.015-$ & 0.0043 \\
0.09 & 0.35 & 1.50 & & & 0.030 & 0.120 & 0.050 & \\
\hline
\end{tabular}

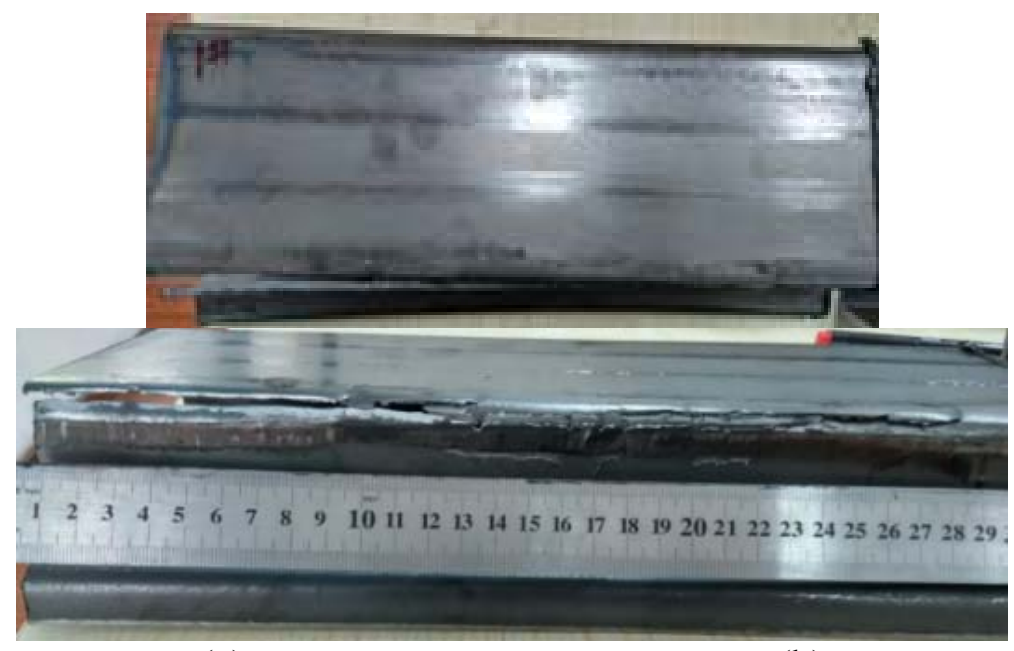

(a)

(b)

Figure 1. Macroscopic feature of specimen: (a) cracked specimen, (b) crack defect

TABLE II. Mechanical Performance of Cracked Specimen

\begin{tabular}{|c|c|c|c|}
\hline Rel /MPa & Rm /MPa & A /\% & Yield ratio \\
\hline 712 & 791 & 22.5 & 0.90 \\
\hline
\end{tabular}




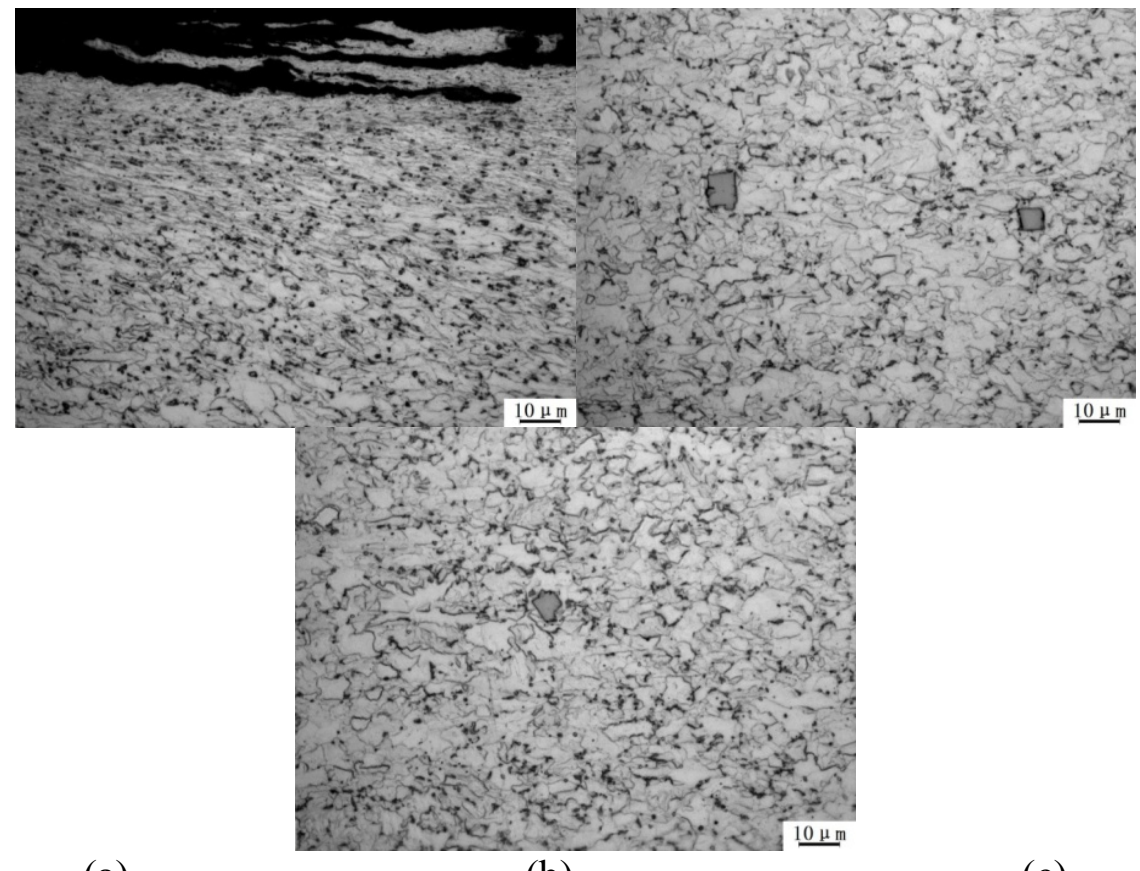

(a)

(b)

(c)

Figure 2. Metallographic structures: (a) edge structure near crack, (b) structure near crack, (c) structure at normal position

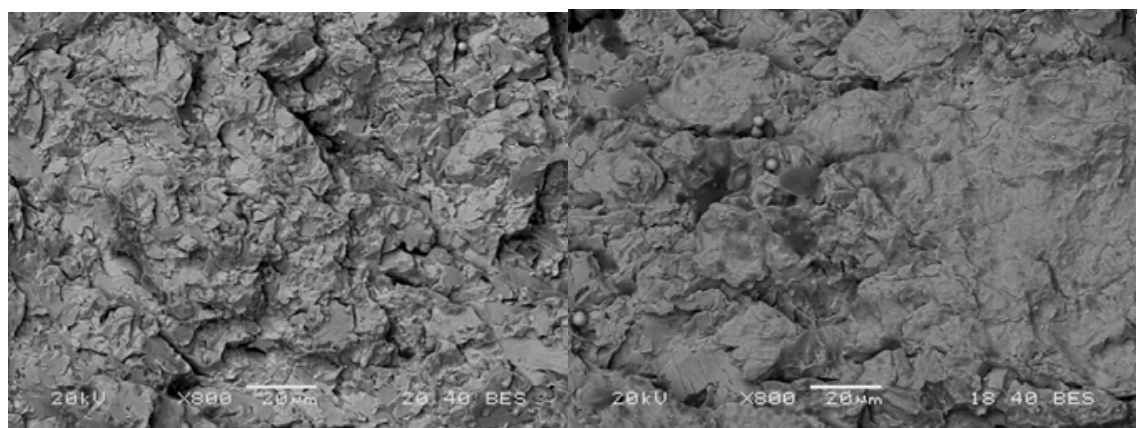

(a) (b)

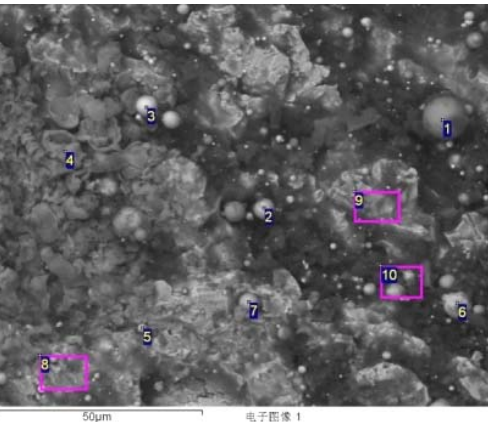

(c)

Figure 3. Fracture morphology of cracked specimen: (a) (b) fracture morphology, (c) precipitates

TABLE III. EDS Results of Precipitates /AT\%

\begin{tabular}{|c|c|c|c|c|c|c|c|c|c|c|c|c|c|}
\hline \multirow{2}{*}{ NO. } & \multicolumn{10}{|c|}{ Elements } \\
\cline { 2 - 15 } & $\boldsymbol{O}$ & $\boldsymbol{A l}$ & $\boldsymbol{S i}$ & $\boldsymbol{P}$ & $\boldsymbol{S}$ & $\boldsymbol{C l}$ & $\boldsymbol{K}$ & $\boldsymbol{C a}$ & $\boldsymbol{T i}$ & $\boldsymbol{V}$ & $\boldsymbol{C r}$ & $\boldsymbol{M n}$ & $\boldsymbol{F e}$ \\
\hline 1 & & 1.74 & & & & & & & 93.35 & 1.12 & & & 3.79 \\
\hline 2 & 2.56 & & 0.49 & & & & & & 2.83 & & & 1.16 & 92.95 \\
\hline 3 & 8.37 & & 1.23 & & 19.75 & & & & 1.87 & & 0.26 & 0.94 & 67.58 \\
\hline 4 & 39.53 & & 0.31 & & & 4.83 & & & & & & & 55.33 \\
\hline 5 & 3.86 & & 0.32 & & 0.65 & & & & 0.18 & & 0.10 & 1.20 & 93.69 \\
\hline 6 & & & 0.29 & & 0.42 & & & & 0.28 & 0.12 & & 1.49 & 97.40 \\
\hline 7 & 5.01 & & 0.53 & & 0.15 & & & & 0.10 & & 1.20 & 1.03 & 91.98 \\
\hline 8 & 9.07 & 0.21 & 0.52 & & 0.33 & & & & & 0.12 & 0.65 & 2.18 & 86.92 \\
\hline 9 & & & 0.43 & 1.58 & & & & & 0.35 & & 0.29 & 1.97 & 95.37 \\
\hline 10 & 20.99 & 0.93 & 1.07 & 1.47 & 0.90 & 0.58 & 0.84 & 1.18 & 1.68 & 0.11 & 2.38 & 1.95 & 65.94 \\
\hline
\end{tabular}




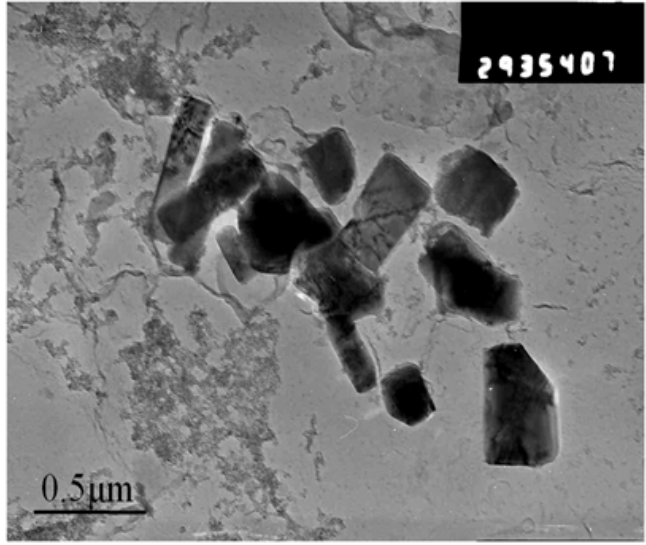

(a)

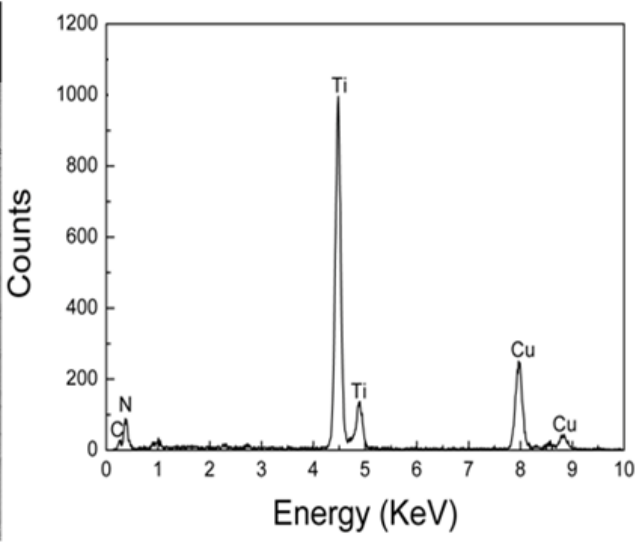

(b)

Figure 4. (a) Liquation TiN morphology; (b) Energy spectrum analysis

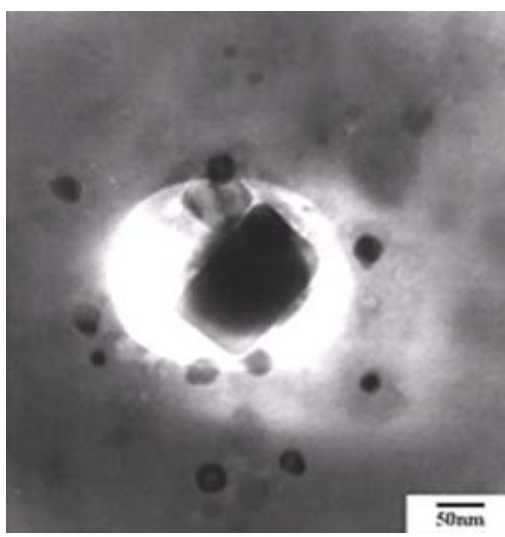

(a)

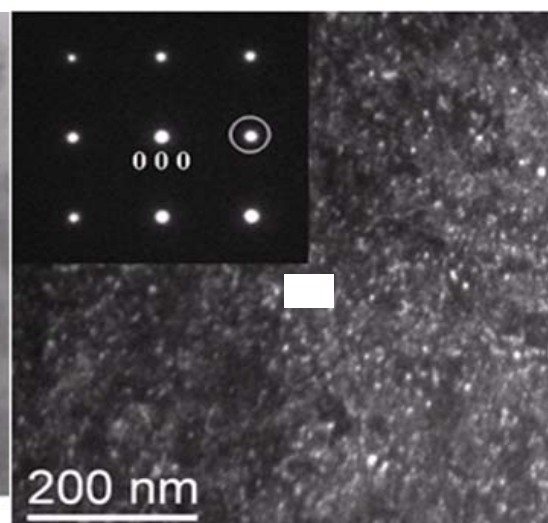

(b) (c)

Figure 5. TiC morphology: (a) $\mathrm{Ti}_{4} \mathrm{C}_{2} \mathrm{~S}_{2}$ and strain induced precipitation $\mathrm{TiC}$ in austenite, (b) supersaturated precipitation $\mathrm{TiC}$ in ferrite, (c) interphase precipitation $\mathrm{TiC}$

\section{Fracture Morphology}

Fracture morphology observation and energy spectrum analysis are shown in Figure 3 and Table III. Obviously, (1) there are no dimple, whole fracture belongs to cleavage fracture, and macroscopic appearance is brittle fracture; (2) spherical precipitates with various sizes distributes at fracture, according to energy spectrum analysis, they are precipitate or oxidation of Ti.

\section{Precipitate Morphology}

Figure 4 shows the morphology of liquation TiN and the result of energy spectrum analysis. As shown, there is phenomenon that multiple square or rectangular TiN particles gather to form a large group.

Figure 5 shows $\mathrm{Ti}_{4} \mathrm{C}_{2} \mathrm{~S}_{2}$ and strain induced precipitation $\mathrm{TiC}$ in austenite, supersaturated precipitation $\mathrm{TiC}$ in ferrite and interphase precipitation $\mathrm{TiC}$. These $\mathrm{TiC}$ precipitates will markedly realize grain refinement and precipitation strengthening, thereby making the experimental steel get high strength.

\section{Analysis and Discussion}

There are many precipitates like $\mathrm{TiN}, \mathrm{TiC}$ and $\mathrm{Ti}_{4} \mathrm{C}_{2} \mathrm{~S}_{2}$ in $\mathrm{Ti}$ micro-alloying steel, they formed from continuous casting process to coiling process. Liquation TiN particle is in micron size, therefore it cannot realize strengthening effect and restrain the grow of austenite grain, however it will consume some $\mathrm{Ti}$ thereby decreasing the precipitate of $\mathrm{Ti}(\mathrm{C}, \mathrm{N})$ during rolling process and reducing the effect of grain refinement and precipitation strengthening[4-6]. Through thermodynamics software 
Thermo-calc, it can be obtained that the liquidus of experimental specimen is around $1500^{\circ} \mathrm{C}$. According to solid solubility product formula of TiN in steel (1) and stoichiometry value of TiN (2) $[7,8]$, the relationship between volume fraction of liquation $\mathrm{TiN}$ and Ti content at $1500^{\circ} \mathrm{C}$ can be obtained.

$$
\begin{aligned}
& \lg \{[T i][N]\}_{L}=5.90-\frac{16586}{T} \\
& \frac{T i-[T i]}{N-[N]}=3.42
\end{aligned}
$$

Where [Ti] and $[\mathrm{N}]$ are quantities of solid solution $\mathrm{Ti}$ and $\mathrm{N}$, respectively;

$\mathrm{T}$ is absolute temperature.

Figure 6 shows the relationship between volume fraction of liquation TiN and Ti content at $1500^{\circ} \mathrm{C}$ with various $\mathrm{N}$ contents $(10,30,50,80,100 \mathrm{ppm})$. Obviously, with a certain $\mathrm{N}$ content, there is a critical Ti content, as shown in Table IV. Critical Ti content decreases with increase of $\mathrm{N}$ content. When Ti content in steel is beyond this critical value, liquation TiN will form. According to Table I, contents of $\mathrm{Ti}$ and $\mathrm{N}$ of experimental specimen are $0.080-0.120 \%$ and $43 \mathrm{ppm}$ respectively, therefore liquation TiN will form.

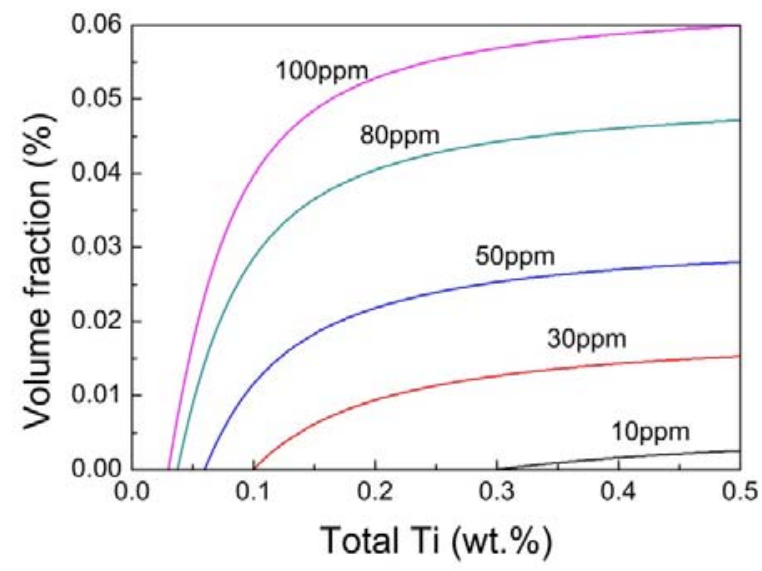

Figure 6. Relationship between volume fraction of liquation $\mathrm{TiN}$ and $\mathrm{Ti}$ content at $1500^{\circ} \mathrm{C}$ with various $\mathrm{N}$ contents

TABLE IV. Critical Ti Content With Various N Content

\begin{tabular}{|c||c|}
\hline N Content & $\begin{array}{c}\text { Critical Ti } \\
\text { content }\end{array}$ \\
\hline \hline $10 \mathrm{ppm}$ & $0.3 \%$ \\
\hline \hline $30 \mathrm{ppm}$ & $0.1 \%$ \\
\hline $50 \mathrm{ppm}$ & $0.07 \%$ \\
\hline $80 \mathrm{ppm}$ & $0.04 \%$ \\
\hline $100 \mathrm{ppm}$ & $0.03 \%$ \\
\hline
\end{tabular}

According to the examination mentioned above: (1) the size of some liquation TiN particles reaches $5-10 \mu \mathrm{m}$, and there are multiple TiN particles gathering to form a large group, they can become origin of crack under stress; (2) the incomplete recrystallization of ferrite grain and cementites gathered at grain boundaries restrain crack propagation hardly; (3) the obvious extrusion on grains at the edge structure near crack and macroscopic phenomenon of metal flaked show that there is mismatching of forming mould thereby leading to processing stress increase. 


\section{Conclusions}

(1) The metallographic structure of experimental specimen is ferrite+pearlite, grain boundary is blurry and cementites gathered there. There is large liquation TiN in ferrite grain, the size reaches 5$10 \mu \mathrm{m}$.

(2) Whole fracture morphology belongs to cleavage fractrure, spherical precipitate or oxidation of Ti with various sizes distributes at fracture.

(3) There is phenomenon that multiple square or rectangular TiN particles gather to form a large group; TiC precipitates markedly realize grain refinement and precipitation strengthening, thereby making the experimental steel get high strength.

(4) The large liquation TiN distributed in grain and the group gathered by multiple liquation TiN can be origin of crack, the mismatching of forming mould leads to large processing stress thereby causing cracking, the metallographic structure showing blurry grain boundaries and cementites gathered there restrains crack propagation hardly, thereby intergranular fracture occurs easily, the fracture morphology characterizes cleavage fracture, macroscopic appearance is brittle fracture.

\section{References}

[1] Takehide S. Physical metallurgy of modern high strength steel sheets [J]. ISIJ International. 2001, 41(6): 520-532.

[2] Y. Q. Liu, T. Peng, L. J. Li, et. al. Research and development of automobile hot rolled HSLA steel in Wuhan Iron and Steel Corp. [J]. Wuhan Iron and Steel Corp. Technology. 2015(03).

[3] R. D. Liu, J. Y. Guo, F. Wang, Research and development of high-strength automobile steel in Ansteel [J]. Shanghai Metals. 2013(04)

[4] X. E. Li, Z. Y. Zhao, R. D. Xue, et. al. The effect of Ti precipitate in hot rolled high-strength steel on performance [J]. Iron \& Steel. 2008(06).

[5] D. D. Sun. Study on microstructure and properties of nanometer Ti precipitation strengthened hot-rolled dual-phase steel [D]. Northeastern University. 2013.

[6] F. Z. Bu. Precipitation behavior and microstructure-property control in Ti microalloyed plate steel [D]. University of Science and Technology Beijing. 2016.

[7] Q. L. Yong, L, Zheng. Solid solubility product formula, stoichiometry value and chemical composition design of micro-alloyed steel [J]. Iron \& Steel. 1988(07).

[8] X. G. Xiong, X. Luo, X. Y. Ye. The influence of $\mathrm{N}$ content on the microstructure and mechanical property of low cost Q345B [C]. Advanced Materials Research, 2014, 1079-1080: 7074. 